\title{
Nicotine dependence and related factors among physicians: results from a cross-sectional survey in Estonia
}

Mariliis Põld ( $\sim$ pold.mariliis@gmail.com )

Estonian Health Insurance Fund https://orcid.org/0000-0001-8531-2799

Kersti Pärna

Tartu Ulikool

Research article

Keywords: physicians, smoking, nicotine dependence, smoking-related factors, Estonia

Posted Date: November 26th, 2019

DOl: https://doi.org/10.21203/rs.2.17810/v1

License: (c) (1) This work is licensed under a Creative Commons Attribution 4.0 International License.

Read Full License 


\section{Abstract}

Background Smoking withdrawal can be difficult due to nicotine dependence (ND). Individual, environmental and social factors must be considered when researching ND. The objective of the present study is to describe ND and to analyse associations between ND and smoking-related and background factors among daily smoking Estonian physicians. Methods A cross-sectional postal survey was used to collect data from Estonian physicians in 2014. The initial sample consisted of all practising physicians in Estonia $(n=5666)$. In total, 2939 physicians participated. The corrected response rate was $53.1 \%$. The current study sample was restricted to physicians who smoked daily $(n=171)$. The outcome variable was ND level, measured using the Fagerström Test for Nicotine Dependence (FTND). The mean age of smoking initiation was calculated, along with the standard deviation and the distribution of ND levels with $95 \%$ confidence intervals (Cls). T-tests and chi-square tests were used to test for differences between groups. To compensate for non-response, the data were weighted. Using multiple logistic regression, the association between ND level (at-least-moderate vs low) and smoking-related and background factors was determined. Crude and fully adjusted odds ratios (ORs) with $95 \%$ Cls were calculated. Results The mean FTND score for daily smoking physicians was $2.8 \pm 2.1$, and $60.8 \%$ of them had low, $33.1 \%$ moderate and $6.1 \%$ high ND levels. The mean age of smoking initiation differed statistically between physicians with low and at-least-moderate ND levels $(21.0 \pm 5.1$ and $18.4 \pm 3.3$, respectively) $(p<0.001)$. In the adjusted model, having at least moderate ND levels was associated with a younger age of smoking initiation ( $\mathrm{OR}=0.82,95 \% \mathrm{Cl} 0.72-0.94)$. After adjustment, ND levels were not significantly associated with the desire to quit, motives to quit and gender. No association was found between ND level and other background factors. Conclusions More than half of daily smoking Estonian physicians had low ND levels. A higher ND level was associated with a younger age of smoking initiation. Knowledge of ND and related factors is useful in the development of smoking cessation counselling services for physicians.

\section{Background}

Physicians are considered to play a significant role in tobacco prevention and cessation (1). However, when physicians are smokers themselves, it is more likely that patients' smoking habits remain unaddressed (2). According to the International Classification of Diseases, tobacco smoking as a substance use disorder is considered a mental and behavioural disease (code F17 in ICD-10) (3). Quitting smoking is often difficult due to nicotine dependence (ND) $(4,5)$. Although the prevalence of smoking has decreased globally (6), smokers in the future might have higher ND, since only those who remain smokers have difficulties quitting, whereas those who find it easy to quit have already done so (5).

In research on ND, the age of tobacco uptake, the speed and magnitude of nicotine delivery, and the development of physical dependence and stimuli-linked associations are among the factors considered $(7,8$. In relation to sociodemographic factors, ND has been described to be higher among men (9), middle-aged adults (10) and ethnic minorities (11). Behavioural factors related to smoking, such as the desire to quit, previous quit attempts and relapses after quitting, have been found to be associated with ND $(12,13)$. Among physicians, medical specialty has also been linked to the prevalence of smoking (14). 
ND is a complex syndrome that involves interaction among individual, environmental and social factors $(7,8)$. Therefore, it is important to investigate factors associated with ND to better promote smoking cessation.

In Estonia, physicians' smoking has been surveyed in 1978, 1982, 2002 and 2014. The age-standardized prevalence of daily smoking has decreased from $39.7 \%$ in 1982 to $14.3 \%$ in 2014 among men and from $12.2 \%$ to $5.2 \%$ among women (15). Questions measuring ND were added to the survey only in 2014 using the six-item Fagerström Test for Nicotine Dependence (FTND). The objective is to describe ND and to analyse the association between ND and smoking-related and background factors among daily smoking Estonian physicians.

\section{Methods}

\section{Design and participants}

The present study followed a cross-sectional survey design. Study data were drawn from Estonian physicians' smoking survey conducted in 2014. Based on the Estonian Health Care Professionals Registry, all practising physicians were included in the initial sampling. Questionnaires were mailed to physicians' $(n=5666)$ home addresses, which were retrieved via data linked to the Estonian population register. In total, 2939 physicians participated in the study. The crude response rate was $51.9 \%$. The corrected response rate (excluding the physicians who were unavailable, had retired, had an incorrect address, had left Estonia or had died) was $53.1 \%$.

FTND questions were only asked of respondents who answered 'yes' to whether they currently smoke every day. Therefore, the present study sample was restricted to physicians who were daily smokers.

\section{Outcome measure}

The outcome variable was the ND level measured by the FTND (16). The test consists of six items. Based on the answers, an ND score in the range of 0 to 10 was produced. A higher score indicates a higher ND level. In the present study, the ND level was determined to be low if the score was $0-3$, moderate if the score was 4-6 or high if the score was 7-10 (17). For logistic regression analysis, the ND level was dichotomized into two categories: low and at least moderate.

\section{Smoking-related factors}

The following factors were included in the analysis: age of initiation of smoking (continuous variable); desire to quit (yes, no, cannot say); main motivation to quit smoking (single-choice question with the following options: personal health problems; wish to set a good example; or other reasons, including material stimulus, increase in the price of tobacco products, social pressure, and cannot say); number of previous quit attempts (none, 1-2, 3-4, 5 and more); stress as the main reason to restart smoking (yes, no); and agreement that smoking is harmful to health (agree, disagree). 
Gender (male, female), age (continuous variable), ethnicity (Estonian, non-Estonian) and medical specialty (family physician, specialist doctor, dentist, other) were included in the model to describe participants' background.

\section{Data analysis}

To compensate for non-response, post-stratification weights were used based on gender and 5-year age groups of the sample of Estonian physicians (18). The mean age of smoking initiation and the mean FTND score, along with standard deviations, were calculated. ND levels with $95 \%$ confidence intervals (Cls) were determined. A t-test was used to test for differences between the mean age of smoking initiation and the mean FTND scores among respondents with low and at-least-moderate ND. The chisquare test was used to test for differences in the distribution of ND levels between men and women. A multiple logistic regression model was used to analyse the association between ND level (at-leastmoderate vs low) and smoking-related and background factors. Crude and fully adjusted odds ratios (ORs) with corresponding $95 \% \mathrm{Cls}$ were calculated.

In total, 171 questionnaires were included in the analysis, excluding questionnaires that lacked information concerning smoking status and FTND questions $(n=13)$.

Data were analysed using the statistical package Stata V 14.0 (19). The study methodology followed the Strengthening the Reporting of Observational Studies in Epidemiology statement guidelines for reporting observational studies (20).

\section{Results}

Among daily smoking Estonian physicians, the mean age was $54.5 \pm 12.6$ years. Most $(79.5 \%)$ were of Estonian ethnicity. More than half of the physicians (55.0\%) were specialist doctors, $19.3 \%$ were dentists, $18.1 \%$ were family physicians, and $7.6 \%$ worked in other positions (e.g., administrative work, clinical research).

\section{Nicotine dependence}

Among daily smoking Estonian physicians, the mean ND score was 2.8 \pm 2.1 . Among men, the mean ND score was $3.2 \pm 2.4$, and among women, it was $2.7 \pm 2.0(p=0.385)$.

More than half of physicians (60.8\%) had a low ND level (Table 1). Men and women did not differ significantly in terms of the distribution of ND levels $(p=0.107)$.

Physicians with low ND levels had a mean age of smoking initiation of $21.0 \pm 5.1$, and physicians with atleast-moderate ND levels had a mean age of initiation of $18.4 \pm 3.3(p<0.001)$. 
In the fully adjusted logistic regression model, having at-least-moderate ND levels was significantly associated with age of smoking initiation (Table 2). When the age of smoking initiation increased by one year, the odds of having at-least-moderate ND levels were $0.82(95 \% \mathrm{Cl} 0.72-0.94)$ times lower. After adjustments were made for all other variables in the model, ND levels were no longer associated with the desire to quit, motives to quit and gender. No significant association was found between ND levels and age, ethnicity or medical specialty.

\section{Discussion}

The present study provided, for the first time, an overview of ND among daily smoking Estonian physicians in Estonia who smoked daily. The aim of the study was to describe ND and to analyse the association between ND and smoking-related and background factors among daily smoking Estonian physicians.

According to the results of the present study, the mean FTND score of Estonian physicians who smoked daily was 2.8 (on a scale of 0 to 10). More than half of daily-smoking Estonian physicians had low ND levels (FTND score 0-3). This result is similar to physicians' nicotine dependence in Germany in 2018 (22) and in Turkey or Greece from approximately 10 years ago $(23,24)$. Compared to the general population worldwide, Estonian physicians' mean FTND score was similar to those in Germany and Norway (score 2.8 in 1990s) but lower than those in the USA (4.0 in the 1990s) and China (3.1 in 2013) $(10,25,26)$. Unfortunately, there is no general population data for Estonia concerning nicotine dependence to add to the comparison.

The results of the fully adjusted logistic regression model showed that nicotine dependence was significantly associated with the age of smoking initiation. The earlier the initiation of smoking was, the higher the odds of having higher nicotine dependence. This result is in accordance with previous findings stating that people who initiate smoking at a younger age are more likely to become nicotine dependent $(27,28)$. Estonian physicians who smoked daily and who had at-least-moderate ND levels began smoking approximately three years earlier than those with low ND levels. Previous results from the smoking survey administered among Estonian physicians showed that in 2014, physicians started smoking at an earlier age than in 1982 or 2002. At the same time, an increasing number of non-smokers enter the profession (15), which creates a situation in which those who smoke have done so beginning at a younger age, while others in the profession will not start at all.

In the present study, after adjustments were made for all descriptive variables, the ND level was not significantly associated with the desire to quit or motives to quit. In crude models, compared to physicians who wished to quit smoking, the odds of having at-least-moderate ND levels were almost three times higher among physicians who did not wish to quit. Similar results were found in surveys conducted in the USA, the UK, Canada and Australia, where a lower level of ND was shown to be related to a higher probability of intentions to quit (29). In the current study, compared to physicians who stated personal health problems as the main motive to quit, the odds of having at-least-moderate ND levels were 
three times higher among those whose main motives were 'other reasons'. This group included, for example, physicians who reported material or social pressure as the main motive to quit. On the one hand, this finding indicates that daily smokers with existing health problems might have already quit. On the other hand, the result could be accounted for by the notion that material reasons, although linked with nicotine dependence among the general population (30), might not be relevant among physicians. As the current study focused on nicotine dependence, motives to quit were not explored in detail here.

The present findings showed no association between ND level and the estimation of the harmfulness of smoking, the number of quit attempts or stress as a reason for relapse. However, some of these factors have been found to be related to ND in previous studies. For example, previous study data reports on the association between work-related stress and smoking intensity among public-sector employees (31) and between work-related stress and the use of addictive substances among physicians (22). These findings would allow us to hypothesize that ND is higher among physicians because the profession is considered to cause higher levels of stress. However, this association was not proven in the current study.

After adjustments were made for background factors, gender ceased to be significantly associated with ND level. The results of the crude models showed that men were almost twice as likely as women to have at-least-moderate ND levels. The results from other studies have similarly shown that men were more likely to have higher nicotine dependence $(25,32)$. The prevalence of daily smoking among men is higher than that among women in Estonia and in the Eastern European region in general (33), as well as among physicians (15).

In the current study, no association was found between ND level and age, ethnicity or medical specialty. The associations might not be evident due to the small sample size, as the prevalence of smoking among physicians was low. In the general population in other countries, ND has been shown to be significantly related to age. High ND has been shown to be more prevalent among 45- to 64-year-olds than among people in younger or older age groups $(10)(32,34)$. In the general population of Estonia, the prevalence of daily smoking among non-Estonians has consistently been higher than that among Estonians (35). Additionally, the prevalence of daily smoking among physicians of non-Estonian ethnicity was somewhat higher than among Estonians (data not shown). However, no indication of the finding that ND would be higher among ethnic minorities was found in the present study sample of physicians. Specifically, general practitioners in Australia tended to smoke less than specialist doctors (14). In Germany, the prevalence of smoking was lower among those in non-surgical specialties than among those in surgical specialties (22).

When the results of the current study are interpreted, some contextual factors should also be considered. Estonia has led a consistent tobacco policy that has resulted in, among other outcomes, smoking being restricted in hospitals. Several Estonian hospitals are smoke-free, and many hospitals actively promote smoking cessation among their staff and, in some cases, pay for cessation treatment. Moreover, according to the previous results, more than half of currently smoking Estonian physicians expressed a desire to quit (36). The results of the present study, however, indicate that smokers might still be facing 
difficulties to do so and therefore would benefit from cessation counselling specifically tailored to physicians' needs.

The methodological limitations of the study are as follows. First, a possible self-representation bias of smokers could contribute to their underreporting of their smoking habits (21). Second, the response rate was just over $53 \%$, and there is no information on non-respondents' smoking habits. The prevalence of smoking might be underestimated, since non-respondents might systematically differ from the respondents. To compensate for non-response, data were weighted based on gender and age. Third, the small sample size, which is related to a low prevalence of smoking among physicians, should be considered. Fourth, respondents who answered 'no' when asked if they currently smoke every day were guided past the FTND questions. This approach limits the sample size to daily smokers only and leaves ND levels among occasional smokers unidentified. Despite these limitations, the smoking survey results for Estonian physicians provide an excellent opportunity to analyse smoking behaviour and nicotine dependence in a sample representing all Estonian physicians. Moreover, physicians comprise a homogenous group in terms of educational background, which can be considered a major strength in a study exploring health behaviour.

\section{Conclusions}

More than half of physicians in Estonia who smoked daily had low nicotine dependence. Higher nicotine dependence among physicians was associated with a younger age of smoking initiation. Knowledge of nicotine dependence and related factors is useful in the development of smoking cessation services targeted towards physicians.

\section{Abbreviations}

ND - nicotine dependence

FTND - Fagerström test for Nicotine Dependence

\section{Declarations}

\section{Ethics approval and consent to participate}

The survey was approved by the Research Ethics Committee of the University of Tartu (Decision No. 235/T-12). An informed consent form, including a description of the study design and information on how the data would be collected and used, was sent to the recipients with the questionnaires. The form explained that participation in the study would be considered to constitute consent. Additional written consent was not obtained.

\section{Consent for publication}


Along with the questionnaires, the recipients were sent a description of the study design and an explanation of how the collected data would be used. Respondents were informed that participation in the study would constitute consent.

\section{Availability of data and materials}

The dataset is available on request.

\section{Competing interests}

The authors declare no competing interests.

\section{Funding}

The design of the Estonian physicians' smoking survey and the collection, analysis, and interpretation of the data were supported by the Estonian Research Council (grant numbers PUT-299, IUT34-17).

\section{Authors' contributions}

MP: performed the statistical analysis, interpreted the data, drafted the manuscript and has been involved in revising the manuscript critically. KP: made a substantial contribution to the conception and the design of the study, interpreted the data and has been involved in revising the manuscript critically. Both authors have read and approved the final manuscript.

\section{Acknowledgements}

The authors would like to thank the entire team involved in designing and conducting the survey in 2014.

\section{References}

1. World Health Organization. The role of health professionals in tobacco control. Geneva: WHO; 2005.

2. Reile R, Pärna K. Do physicians address their patients' smoking behavior? Results from a nationwide survey among physicians in Estonia. Public Health. 2018;doi.org/10.1016/j.puhe.2018.02.009.

3. World Health Organization. International Statistical Classification of Diseases and Related Health Problems 10th Revision (ICD-10). Geneva: WHO; 2016.

4. DiFranza JR, Savageau JA, Rigotti NA, Fletcher K, Ockene JK, McNeill AD, et al. Development of symptoms of tobacco dependence in youths: 30 month follow up data from the DANDY study. Tob Control. 2002;11:228-35.

5. Mendelsohn CP. Nicotine dependence. Why is it so hard to quit smoking? Med Today. 2011;12:3540.

6. World Health Organization. WHO global report on trends in prevalence of tobacco smoking 20002025, second edition. Geneva: WHO; 2018. 
7. Balfour DJK. The psychobiology of nicotine dependence. Eur Respir Rev. 2008;doi:10.1183/09059180.00011001.

8. Hatsukami DK, Stead LF, Gupta PC. Tobacco addiction. Lancet. 2008;doi:10.1016/S01406736(08)60871-5.

9. Allen AM, Scheuermann TS, Nollen N, Hatsukami D, Ahluwalia JS. Gender differences in smoking behavior and dependence motives among daily and nondaily smokers. Nicotine Tob Res. 2016;doi:10.1093/ntr/ntv138.

10. Li H, Zhou Y, Li S, Wang Q, Pan L, Yang X, et al. The relationship between nicotine dependence and age among current smokers. Iran J Public Health. 2015;44:495-500.

11. Breslau N, Johnson EO, Hiripi E, Kessler R. Nicotine dependence in the United States. Arch Gen Psychiatry. 2003;58:810-6.

12. Hakim S, Chowdhury MAB, Uddin MJ. Correlates of attempting to quit smoking among adults in Bangladesh. Addict Behav Reports. 2018doi.org/10.1016/j.abrep.2018.04.002

13. Zhou X, Nonnemaker J, Sherrill B, Gilsenan AW, Coste F, West R. Attempts to quit smoking and relapse: factors associated with success or failure from the ATTEMPT cohort study. Addict Behav. 2009;34:365-73.

14. Smith DR, Leggat $P$. The historical decline of tobacco smoking among Australian physicians: 19641997. Tob Induc Dis. 2008;doi:10.1186/1617-9625-4-13.

15. Pärna K, Põld M, Ringmets I. Trends in smoking behaviour among Estonian physicians in 19822014. BMC Public Health. 2017; doi:10.1186/s12889-017-4596-x.

16. Heatherton T, Kozlowski L, Frecker R, Fagerström K. The Fagerstrom Test for Nicotine Dependence: a revision of the Fagerstrom Tolerance Questionnaire. Br J Addict. 1991;86:1119-27.

17. Fagerström K, Russ C, Yu CR, Yunis C, Foulds J. The Fagerström Test for Nicotine Dependence as a predictor of smoking abstinence: A pooled analysis of varenicline clinical trial data. Nicotine Tob Res. 2012;14:1467-73.

18. Raag M, Pärna K. Cigarette smoking and smoking- attributable diseases among Estonian physicians: a cross-sectional study. BMC Public Health. 2018;doi: 10.1186/s12889-018-5105-6.

19. Stata. StataCorp, College Station, Texas 77845-4512, USA.

20. Vandenbroucke JP, von Elm E, Altman DG, Gøtzsche PC, Mulrow CD, Pocock SJ, et al. Strengthening the Reporting of Observational Studies in Epidemiology (STROBE): explanation and elaboration. PLoS Med. 2007;4:e297.

21. Patrick DL, Cheadle A, Thompson DC, Diehr P, Koepsell T, Kinne S. The validity of self-reported smoking: A review and meta-analysis. Am J Public Health. 1994;84:1086-93.

22. Pförringer $D$, Mayer $R$, Meisinger $C$, Freuer $D$, Eyer $F$. Health, risk behaviour and consumption of addictive substances among physicians - results of an online survey. J Occup Med Toxicol. 2018;doi.org/10.1186/s12995-018-0208-7. 
23. Saglam L, Bayraktar R, Kadioglu EE, Acemoglu H. Smoking prevalance and the degree of nicotine dependence among healthcare workers at the Ataturk University medical facility. Eurasian J Med. 2010;42:74-7.

24. Papadopoulos A, Katsardi M, Koutsojannis C. Nicotine addiction among physicians in Greece. Ann Gen Psychiatry. 2008;doi:10.1186/1744-859X-7-S1-S340.

25. Fagerström K, Furberg H. A comparison of the Fagerström Test for Nicotine Dependence and smoking prevalence across countries. Addiction. 2008;103:841-5.

26. Kim SS, Fang H, DiFranza J, Ziedonis DM, Ma GX. Gender differences in the Fagerström Test for Nicotine Dependence in Korean Americans. J Smok Cessat. 2012;doi:10.1017/jsc.2012.5.

27. Breslau N, Fenn N, Peterson EL. Early smoking initiation and nicotine dependence in a cohort of young adults. Drug Alcohol Depend. 1993;33:129-37.

28. Hwang JH, Park SW. Age at smoking initiation and subsequent smoking among Korean adolescent smokers. J Prev Med Public Heal. 2014;doi.org/10.3961/jpmph.14.032

29. Siahpush M, McNeill A, Borland R, Fong GT. Socioeconomic variations in nicotine dependence, selfefficacy, and intention to quit across four countries: findings from the International Tobacco Control (ITC) Four Country Survey. Tob Control. 2006;doi: 10.1136/tc.2004.008763.

30. Hobkirk AL, Krebs NM, Muscat JE. Income as a moderator of psychological stress and nicotine dependence among adult smokers. Addict Behav. 2018;doi.org/10.1016/j.addbeh.2018.04.021.

31. Kouvonen A, Kivimäki M, Virtanen M, Pentti J, Vahtera J. Work stress, smoking status, and smoking intensity: an observational study of 46190 employees. J Epidemiol Community Health. 2005;59:639.

32. Schnoll RA, Goren A, Annunziata K, Suaya JA. The prevalence, predictors and associated health outcomes of high nicotine dependence using three measures among US smokers. Addiction. 2013; doi:10.1111/add.12285.

33. Eurostat. Tobacco consumption statistics. Accessed May, 2019.

34. Goodwin R, Pagura J, Spiwak R, Lemeshow A, Sareen J. Predictors of persistent nicotine dependence among adults in the United States. Drug Alcohol Depend. 2011;118:127-33.

35. National Institute for Health Development. Health behaviour among Estonian adult population study. TKU52: Smoking by sex and nationality. Accessed May, 2019.

36. Põld M, Pärna K. Factors associated with desire to quit smoking among Estonian physicians: Crosssectional data of 2002 and 2014. Tob Prev Cessat. 2018;doi.org/10.18332/tpc/93009.

\section{Tables}

Table 1. Weighted prevalence of nicotine dependence levels (\%) among Estonian physicians smoking daily, 2014. 


\begin{tabular}{|l|r|r|r|r|r|r|}
\hline \multirow{2}{*}{ ND level } & \multicolumn{2}{|c|}{ Men } & \multicolumn{2}{c|}{ Women } & \multicolumn{2}{c|}{ Total } \\
\cline { 2 - 7 } & \multicolumn{1}{|c|}{$95 \% \mathrm{Cl}$} & \multicolumn{1}{c|}{$\%$} & \multicolumn{1}{c|}{$95 \% \mathrm{Cl}$} & \multicolumn{1}{c|}{$\%$} & \multicolumn{1}{c|}{$95 \% \mathrm{Cl}$} \\
\hline Low & 51.6 & $38.8-64.1$ & 67.8 & $58.4-76.0$ & 60.8 & $53.1-68.0$ \\
\hline Moderate & 41.3 & $29.4-54.4$ & 26.8 & $19.3-36.0$ & 33.1 & $26.3-40.7$ \\
\hline High & 7.1 & $2.64-17.8$ & 5.4 & $2.4-11.5$ & 6.1 & $3.3-11.1$ \\
\hline
\end{tabular}

Table 2. Nicotine dependence level and factors associated with nicotine dependence among Estonian physicians smoking daily, 2014.

\begin{tabular}{|c|c|c|c|c|}
\hline \multirow[t]{2}{*}{ Variables } & \multicolumn{2}{|c|}{$\begin{array}{c}\text { ND level }(\%) \\
\end{array}$} & \multirow{2}{*}{$\begin{array}{l}\text { Crude OR } \\
(95 \% \mathrm{Cl})\end{array}$} & \multirow{2}{*}{$\begin{array}{l}\text { Adjusted OR* } \\
(95 \% \mathrm{Cl})\end{array}$} \\
\hline & Low & At-least-moderate & & \\
\hline \multicolumn{5}{|l|}{ Smoking-related factors } \\
\hline Age of smoking initiation $\star \star$ & & & $0.83(0.74-0.92)$ & $0.82(0.72-0.94)$ \\
\hline \multicolumn{5}{|l|}{ Desire to quit } \\
\hline Yes & 61.8 & 48.4 & 1 & 1 \\
\hline No & 15.8 & 35.5 & $2.88(1.33-6.21)$ & $1.89(0.71-5.04)$ \\
\hline Cannot say & 22.4 & 16.1 & $0.92(0.40-2.13)$ & $0.88(0.31-2.44)$ \\
\hline \multicolumn{5}{|l|}{ Motivation to quit } \\
\hline Personal health problems & 68.5 & 66.3 & 1 & 1 \\
\hline Wish to set a good example & 10.2 & 5.2 & $0.53(0.16-1.82)$ & $0.79(0.19-3.31)$ \\
\hline Other & 6.2 & 17.9 & $3.00(1.06-8.52)$ & $2.67(0.63-11.30)$ \\
\hline Cannot say & 15.1 & 10.6 & $0.72(0.28-1.85)$ & $0.55(0.20-1.55)$ \\
\hline \multicolumn{5}{|l|}{ Previous quit attempts } \\
\hline None & 23.6 & 34.0 & 1 & \\
\hline $1-2$ & 43.9 & 38.9 & $0.61(0.29-1.31)$ & $0.60(0.24-1.51)$ \\
\hline $3-4$ & 20.6 & 21.7 & $0.73(0.29-1.82)$ & $0.72(0.24-2.14)$ \\
\hline 5 and more & 11.9 & 5.4 & $0.32(0.07-1.30)$ & $0.26(0.05-1.44)$ \\
\hline \multicolumn{5}{|c|}{ Stress as main reason for relapse } \\
\hline No & 63.4 & 64.0 & 1 & 1 \\
\hline Yes & 36.6 & 36.0 & $0.97(0.50-1.89)$ & $1.66(0.73-3.79)$ \\
\hline \multicolumn{5}{|c|}{ Smoking is very harmful to health } \\
\hline No & 41.5 & 51.2 & 1 & 1 \\
\hline Yes & 58.5 & 48.8 & $0.68(0.36-1.27)$ & $1.11(0.50-2.45)$ \\
\hline \multicolumn{5}{|l|}{ Background factors } \\
\hline \multicolumn{5}{|l|}{ Gender } \\
\hline Male & 36.7 & 53.5 & 1 & 1 \\
\hline Female & 63.3 & 46.5 & $0.51(0.27-0.96)$ & $0.77(0.34-1.75)$ \\
\hline Age ${ }^{\star *}$ & & & $1.00(0.98-1.03)$ & $1.02(0.99-1.06)$ \\
\hline \multicolumn{5}{|l|}{ Ethnicity } \\
\hline Estonian & 80.4 & 75.6 & 1 & 1 \\
\hline Non-Estonian & 19.6 & 24.4 & $1.33(0.62-2.84)$ & $1.55(0.60-4.00)$ \\
\hline \multicolumn{5}{|l|}{ Medical specialty } \\
\hline Family physician & 17.1 & 16.7 & 1 & \\
\hline Specialist doctor & 52.4 & 61.7 & $1.21(0.52-2.79)$ & $1.05(0.35-3.13)$ \\
\hline Dentist & 23.5 & 12.2 & $0.53(0.17-1.61)$ & $0.61(0.17-2.23)$ \\
\hline Other & 7.0 & 9.4 & $1.37(0.36-5.14)$ & $1.21(0.22-6.48)$ \\
\hline
\end{tabular}


*Adjusted to all other variables in the table. ** Continuous variable. 